COPYRIGHT @ 2021 INTERNATIONAL JOURNAL OF SCIENCE DENTISTRY | AVAILABLE ONLINE http://www.periodicos.uff.br/index

\title{
AVALIAÇÃO DE DIVERSAS FORMAS DE DESINFECÇÃO DO ALGINATO COM CLOREXIDINA
}

Evaluation of different forms of impression material disinfection using chlorhexidine

\section{Karin de Mello Weig}

Professora do Departamento de Odontotécnica da Universidade Federal Fluminense, Niterói/RJ, Brasil

\section{Julia Araújo de Souza}

Graduada em Odontologia pela Universidade Federal Fluminense, Niterói/RJ, Brasil

\section{Carolina Paes Borge}

Graduada em Odontologia pela Universidade Federal Fluminense, Niterói/RJ, Brasil

\section{Thales Ribeiro de Magalhães Filho}

Professor do Departamento de Odontotécnica da Universidade Federal Fluminense, Niterói/RJ, Brasil

\section{Rosana Rocha Barros}

Professora do Departamento de Microbiologia e Parasitologia da Universidade Federal Fluminense, Niterói/RJ, Brasil

Universidade Federal Fluminense

Faculdade de Odontologia

Artigo Original

Karin de Mello Weig

Endereço: Rua Mário Santos Braga, 28- Centro, Niterói-RJ, 24020-140

Telefone: (21) 98803-4400

E-mail: karin.weig@uol.com.br 


\section{RESUMO}

O alginato é um material usado na odontologia para moldagem de arcada dentária. Sua propriedade de embebição permite absorver fluidos da cavidade oral, que infectam o molde e o modelo de gesso. Por isso a importância da desinfecção, prevenindo contaminação e potencial infecção cruzada. O objetivo deste estudo foi analisar a eficácia da clorexidina associada ao alginato na inibição do crescimento de microrganismos presentes na cavidade oral. $\mathrm{O}$ alginato foi avaliado de 4 formas distintas: sem clorexidina; com clorexidina borrifada após geleificação, com clorexidina incorporada em sua fórmula e manipulado com clorexidina $0,3 \%$. No teste in vitro a eficácia foi avaliada frente a uma cultura de Streptococcus mutans. No teste in vivo foram feitas moldagens em 4 voluntários e os moldes de alginato e modelos de gesso avaliados microbiologicamente. Ambos os testes foram semeados em ágar sangue, incubados a $35^{\circ} \mathrm{C}$ por 20h e feita observação visual de crescimento bacteriano. Como resultado obteve-se: no teste in vitro houve crescimento bacteriano somente no alginato sem a clorexidina; já nos testes in vivo o alginato borrifado com clorexidina não teve crescimento em $75 \%$ dos modelos de gesso; os alginatos com clorexidina diluída, incorporada e sem clorexidina não tiveram crescimento em 12,5\% dos modelos. Como conclusão obteve-se que a clorexidina foi eficiente na inibição do crescimento do $S$. mutans, mas aumentando a população bacteriana, o método mais efetivo foi a clorexidina borrifada, diminuindo o risco de infecção cruzada.

Palavras-chave: alginato, desinfecção, clorexidina, alginate, desinfection, chlorhexidine

\section{ABSTRACT}

Alginate is a material used in dentistry for dental arch molding. Its imbibing property allows it to absorb oral fluids, which infect the mold and plaster model. Therefore disinfection is very important to prevent contamination and potential cross infection. The 
objective of this study was to analyze the efficacy of alginate-associated chlorhexidine in inhibiting the growth of microorganisms present in the oral cavity. The alginate was analized in 4 different forms: no chlorhexidine; with chlorhexidine sprinkled after gelation, chlorhexidine incorporated into its formula and handled with $0.3 \%$ chlorhexidine. In the in vitro test its efficacy was evaluated considering a culture of Streptococcus mutans during the manipulation. In the in vivo test 4volunteers were molded and the alginate molds and plaster models were avaluated microbiologic. Both tests were seeded on blood agar, incubated at $35^{\circ} \mathrm{C}$ for $20 \mathrm{~h}$, and visual observation of bacterial growth. As a result it was obtained: in the in vitro test there was bacterial growth only in alginate without chlorhexidine; already in the in vivo test the alginate sprinkled with chlorhexidine had no bacterial growth in $75 \%$ of the gypsum models; the alginates with chlorhexidine diluted, incorporated and without chlorhexidine had no bacterial growth in $12.5 \%$ of the models. As a conclusion, chlorhexidine was efficient in inhibiting the growth of S. mutans but increasing the bacterial population. The most effective method was chlorhexidine sprayed, reducing the risk of cross infection.

Keywords: alginato, desinfecção, clorexidina, alginate, desinfection, chlorhexidine

\section{INTRODUÇÃO}

O alginato é um hidrocolóide irreversível, amplamente usado por cirurgiões-dentistas na moldagem da arcada dentária dos pacientes. Possui como principal ingrediente ativo um alginato solúvel, como os de potássio, sódio e trietanolamina. No processo de geleificação há a formação do alginato insolúvel, em que há uma reação do alginato solúvel com íons cálcio 
do sulfato de cálcio, a partir da mistura da água com pó do alginato (ANUSAVICE K. J. et al, 2013).

A preferência dos dentistas pelo alginato se deve aos fatos dele ser de baixo custo, sabor agradável, fácil manipulação, boa reprodutibilidade e fácil limpeza (MAIA S.C.M., 2016). Apesar de todas essas qualidades esse material pode ser um meio transmissor de microrganismos patogênicos, tais como Enterobacter cloacae, Pseudomonas aerugenosa, Staphylococcus aureus e Mycobacterium tuberculosis (POWELL G.L. et al, 1990). No processo da moldagem, ao entrar em contato com a cavidade oral do paciente, no alginato, por este ter a propriedade de embebição, podem ser absorvidos fluidos como saliva e sangue, além de microrganismos (OSÓRIO A.F. et al, 1998). Se não houver a desinfecção, esses microrganismos também podem ser transmitidos para o modelo de gesso, que poderá contaminar, posteriormente, os profissionais envolvidos (POWELL G.L. et al, 1990; OSÓRIO A.F. et al, 1998). Portanto, a desinfecção do alginato torna-se indispensável para o controle das possíveis doenças causadas por microrganismos.

A desinfecção deve ser feita por agentes que tenham uma satisfatória ação antimicrobiana e que não alterem o resultado da moldagem, interferindo o mínimo possível na estabilidade do material (MAIA S.C.M., 2016). Existem diversas formas de desinfecção, sendo elas: hipoclorito de sódio, clorexidina, álcool 70\%, glutaraldeído em imersão e em aerossol e ainda alginatos fabricados com componentes desinfetantes em sua formulação (MAIA S.C.M., 2016; EGUSA H. et al, 2008; BORGO L.F. et al, 2018; PAKDIN M. et al, 2016).

A clorexidina é um antisséptico sintético que apresenta alto nível de atividade sem, no entanto, ter os efeitos secundários indesejáveis que a maioria dos antimicrobianos apresenta (HORTENSE S.R. et al, 2010). Pequenas concentrações de sais de clorexidina 
são capazes de atuar na parede celular de bactérias, levando à ruptura da célula, além do que, sendo praticamente isenta de toxicidade e efeitos corrosivos, proporciona extrema segurança no seu emprego (RUSSEL A.D., 1986; MARION J. et al, 2013). Na odontologia é usada na forma de sal digluconato de clorexidina, em solução aquosa (LOPES H.P. \& SIQUEIRA JR J.F., 2015). Ela possui em sua estrutura dois anéis clorofenólicos nas suas extremidades ligados a um grupamento biguanida em cada lado e conectados por uma cadeia central de hexametileno. Em baixas concentrações ela é considerada bacteriostática (inibe o crescimento de bactérias) e em altas concentrações é bactericida (elimina grande parte da população de bactérias) e apresenta amplo espectro de atividade antibacteriana, atuando contra espécies Gram-positivas e Gram-negativas (RUSSEL A.D., 1986; LOPES H.P. \& SIQUEIRA JR J.F., 2015). A clorexidina é utilizada na periodontia para redução de placas e como terapia de suporte de doenças periodontais, e também na endodontia, pelos efeitos inibitórios em bactérias nos canais radiculares; são preconizadas as concentrações de $0,12 \%$ a $2 \%$ em seu uso clínico (MARION J. et al, 2013; LOPES H.P. \& SIQUEIRA JR J.F., 2015).

Recentemente, foi apresentado no mercado um tipo de alginato que é comercializado já com a clorexidina em sua composição, o que configuraria uma propriedade autodesinfetante do alginato, dispensando o processo de desinfecção. Alguns estudos comprovam a eficiência da clorexidina no alginato quanto à ação antimicrobiana (MOREIRA A.C.A. \& WANDERLEY-CRUZ J.F., 2005; ESTEVES R.A. et al, 2007), entretanto não são encontradas outras pesquisas sobre esse tipo de alginato comercializado atualmente.

Devemos lembrar também que todas as etapas de moldagem devem ser consideradas para a fidelidade do molde e posteriormente sucesso do tratamento. Seguir as orientações do REVISTA FLUMINENSE DE ODONTOLOGIA - ANO XXVII - No 55 - Janeiro / Julho 2021 
fabricante é a melhor maneira de contornar os diversos fatores que levam a distorções de molde e modelo (OSHIRO FILHO N.T. et al, 2018).

Considerando os dados acima, o objetivo deste estudo foi analisar a eficácia da clorexidina associada ao alginato na inibição do crescimento do Streptococcus mutans e de microrganismos na cavidade oral de voluntários.

\section{MATERIAIS E MÉTODOS}

Esta pesquisa foi aprovada pelo Comitê de Ética em Pesquisa da Universidade Federal Fluminense e está de acordo com seus padrões éticos e com a Declaração de Helsinki de 1975. Número de aprovação: 2.207.887.

O estudo in vitro foi realizado utilizando diferentes apresentações do alginato, com ou sem clorexidina, frente a suspensões bacterianas de Streptococcus mutans INCQS 446 (ATCC 25175), na concentração final de $3 \times 10^{7} \mathrm{UFC} / \mathrm{ml}$. Como controle negativo, as mesmas apresentações do alginato com ou sem clorexidina foram avaliadas sem adição de microrganismos.

Foram confeccionados corpos de prova redondos $(0,5 \mathrm{~cm}$ de altura $\mathrm{x} 0,5 \mathrm{~cm}$ de diâmetro) de alginato na concentração normalmente utilizada na prática ( $8 \mathrm{~g} / 15 \mathrm{ml}$ de diluente) em quatro diferentes preparações. Preparação SmA: alginato sem clorexidina, com suspensão bacteriana. Preparação SmCB: alginato sem clorexidina, com suspensão bacteriana; depois de confeccionados, os corpos de prova foram borrifados com solução de clorexidina $0,3 \%$. Preparação SmCI: alginato com clorexidina incorporada pelo fabricante, com suspensão bacteriana. Preparação SmCD: alginato preparado com solução de clorexidina $0,3 \%$, 
possuindo uma concentração final de $0,15 \%$, e com suspensão bacteriana. Todas as preparações foram feitas em triplicata e os corpos de prova foram inoculados em $5 \mathrm{ml} \mathrm{de}$ caldo BHI e incubados a $35^{\circ} \mathrm{C}$ por $20 \mathrm{~h}$.

Para os controles negativos (grupos A, CB, CD e CI) foram preparados corpos de prova de alginato nas mesmas apresentações, sem a adição de suspensão bacteriana. Os mesmos foram inoculados em caldo BHI e incubados sob as mesmas condições do grupo teste.

A viabilidade da cultura de Streptococcus mutans foi avaliada inoculando a mesma suspensão utilizada nos testes em caldo BHI e incubada sob as mesmas condições, sendo este o controle positivo (grupo Sm).

Após o período de incubação, cada tubo de caldo BHI contendo um corpo de prova de alginato em sua respectiva apresentação foi semeado em ágar sangue e incubado a $35^{\circ} \mathrm{C}$ por 20h. Foi realizada a observação visual do crescimento bacteriano. No estudo in vivo foram feitas moldagens parciais em 4 voluntários. Foram utilizadas 4 moldeiras parciais para a moldagem de cada hemiarcada dos voluntários, cada uma contendo uma das preparações testadas, sendo elas: alginato sem clorexidina, alginato com clorexidina $0,3 \%$ borrifada após a geleificação, alginato com clorexidina na sua composição e alginato com clorexidina com concentração final de $0,15 \%$ substituindo parte da água na manipulação. Após a geleificação das preparações do alginato, os mesmos foram submetidos à avaliação microbiológica. Foi friccionado um swab estéril em cada molde e este foi inoculado em tubo contendo caldo BHI.

Logo depois, foi realizada a manipulação do gesso tipo IV para a confecção de modelos de gesso das moldagens realizadas nos voluntários. Após a cristalização do gesso, os mesmos 
também foram submetidos à avaliação microbiológica, da mesma forma dos moldes de alginato.

Os tubos com caldo BHI foram incubados a $35^{\circ} \mathrm{C}$ por $20 \mathrm{~h}$. Após o período de incubação, cada tubo de caldo BHI, contendo o swab dos respectivos testes em moldes de alginato e modelos de gesso, foi semeado em ágar sangue e incubado a $35^{\circ} \mathrm{C}$ por $20 \mathrm{~h}$, sendo realizada a observação visual do crescimento bacteriano após o período de incubação.

\section{RESULTADOS}

No estudo in vitro as preparações SmCB (alginato borrifado com solução de clorexidina e suspensão de $S$. mutans), SmCI (alginato com clorexidina incorporada pelo fabricante e suspensão de $S$. mutans) e SmCD (alginato preparado com solução de clorexidina e suspensão de $S$. mutans) não foi possível observar crescimento bacteriano (figuras 1 e 2). Na preparação SmA (alginato sem clorexidina e suspensão de $S$. mutans) houve crescimento bacteriano, entretanto, pudemos observar uma ligeira inibição desse crescimento (figura 3). Nos controles positivos (cultura de $S$. mutans) e negativos (preparações de alginato sem microrganismos) constatou-se respectivamente resultados positivos e negativos (figuras $1 \mathrm{e}$ 4). A tabela 1 mostra os grupos testados e seus respectivos resultados. 


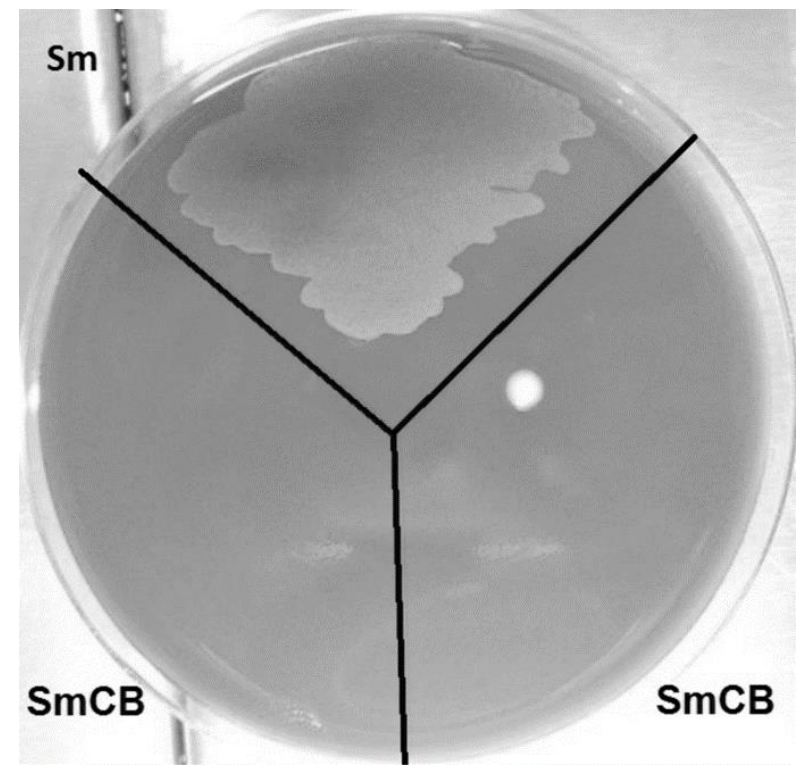

Figura 1: Grupos Sm (controle positivo) e SmCB em ágar sangue.

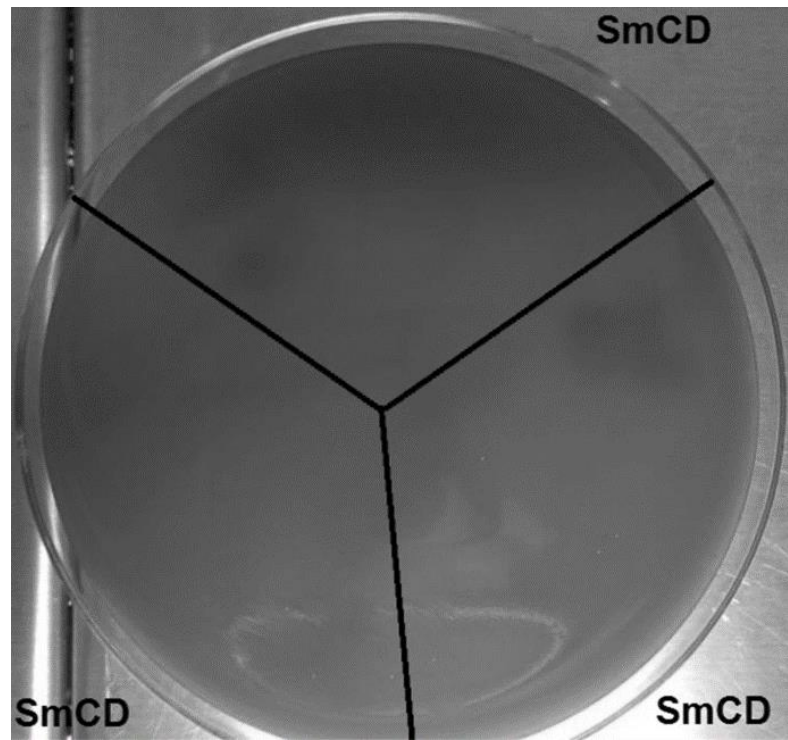

Figura 2: grupo SmCD em ágar sangue. Imagem também representativa do grupo SmCI, por terem a mesma apresentação visual neste meio de cultura. 


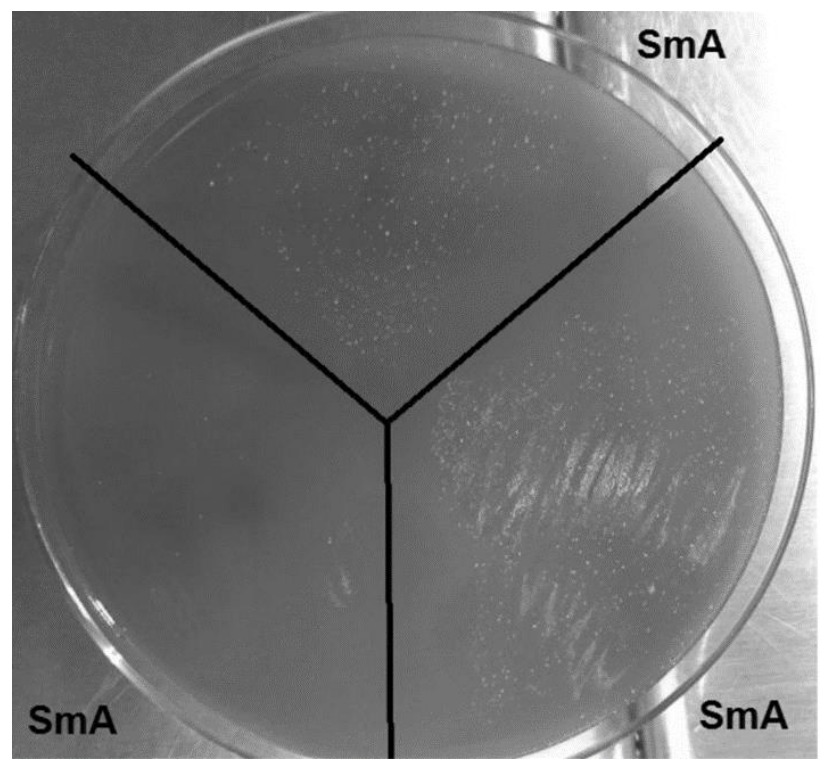

Figura 3: grupo SmA em ágar sangue.

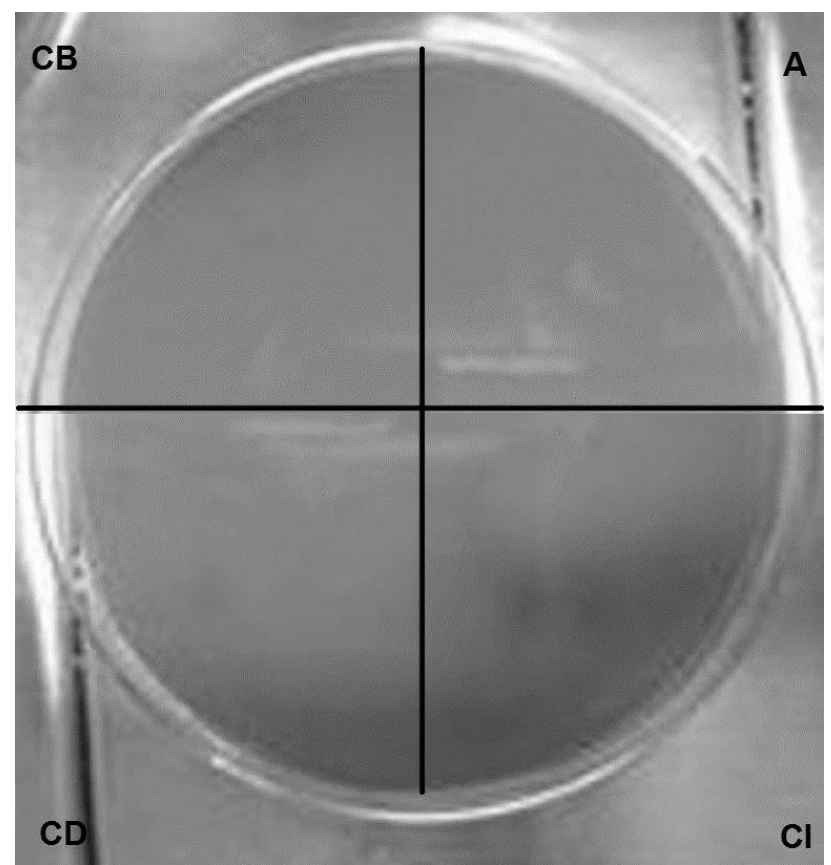

Figura 4: controles negativos (grupos A, CB, CD e CI) em ágar sangue. 


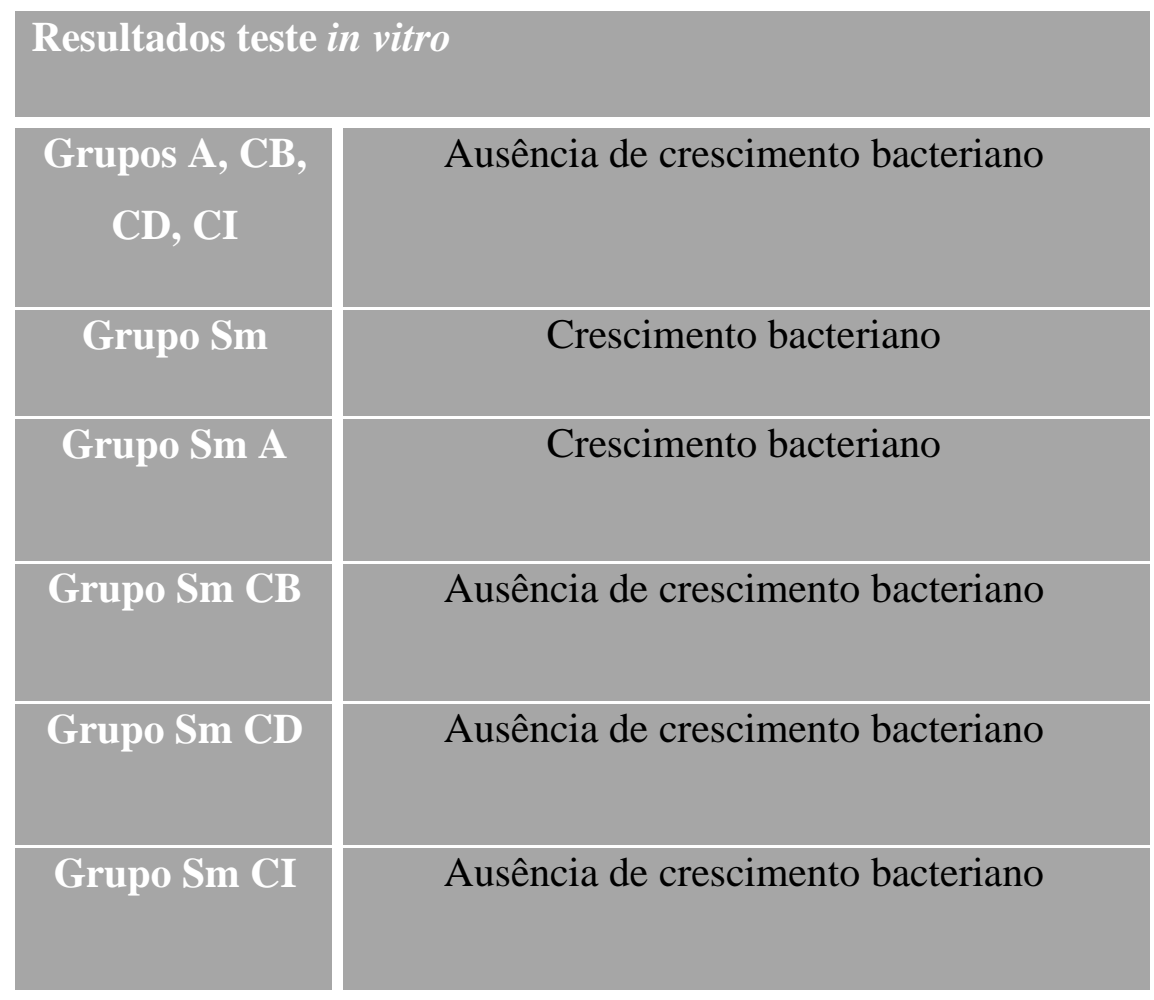

Tabela 1: Resultados do teste in vitro.

No estudo in vivo quatro voluntários foram submetidos a dois experimentos independentes. Os resultados obtidos no primeiro experimento foram similares aos do segundo, exceto por um resultado discordante em que houve ausência de crescimento no modelo de gesso oriundo do molde de alginato sem tratamento com clorexidina no voluntário I. A população de microrganismos da cavidade oral de todos os voluntários foi inibida quando o molde de alginato foi borrifado com clorexidina. Esta inibição do crescimento bacteriano também foi observada no modelo de gesso oriundo deste molde, exceto em um voluntário, onde foi possível observar crescimento bacteriano no modelo de gesso oriundo do molde de alginato borrifado com clorexidina. A clorexidina diluída ou incorporada no alginato não foi capaz de inibir a população bacteriana nos moldes de alginato. O mesmo padrão se repete nos modelos de gesso oriundos destes moldes, 
exceto de um voluntário em que não observou-se crescimento no modelo de gesso oriundo do molde feito com clorexidina diluída. Para a maior parte dos voluntários, o uso de clorexidina borrifada no molde de alginato é capaz de inibir o crescimento bacteriano no modelo de gesso, portanto, elimina o risco de contaminação cruzada no transporte/manipulação pelo protético. Observa-se uma discreta variabilidade de resultados entre os voluntários, o que provavelmente se deve a características inerentes à microbiota oral de cada indivíduo. No Gráfico 1 podemos observar os dados referentes aos resultados que foram evidenciados por colunas representando o crescimento bacteriano. No caso do alginato do grupo CB a ausência da coluna simboliza que o crescimento bacteriano foi nulo.

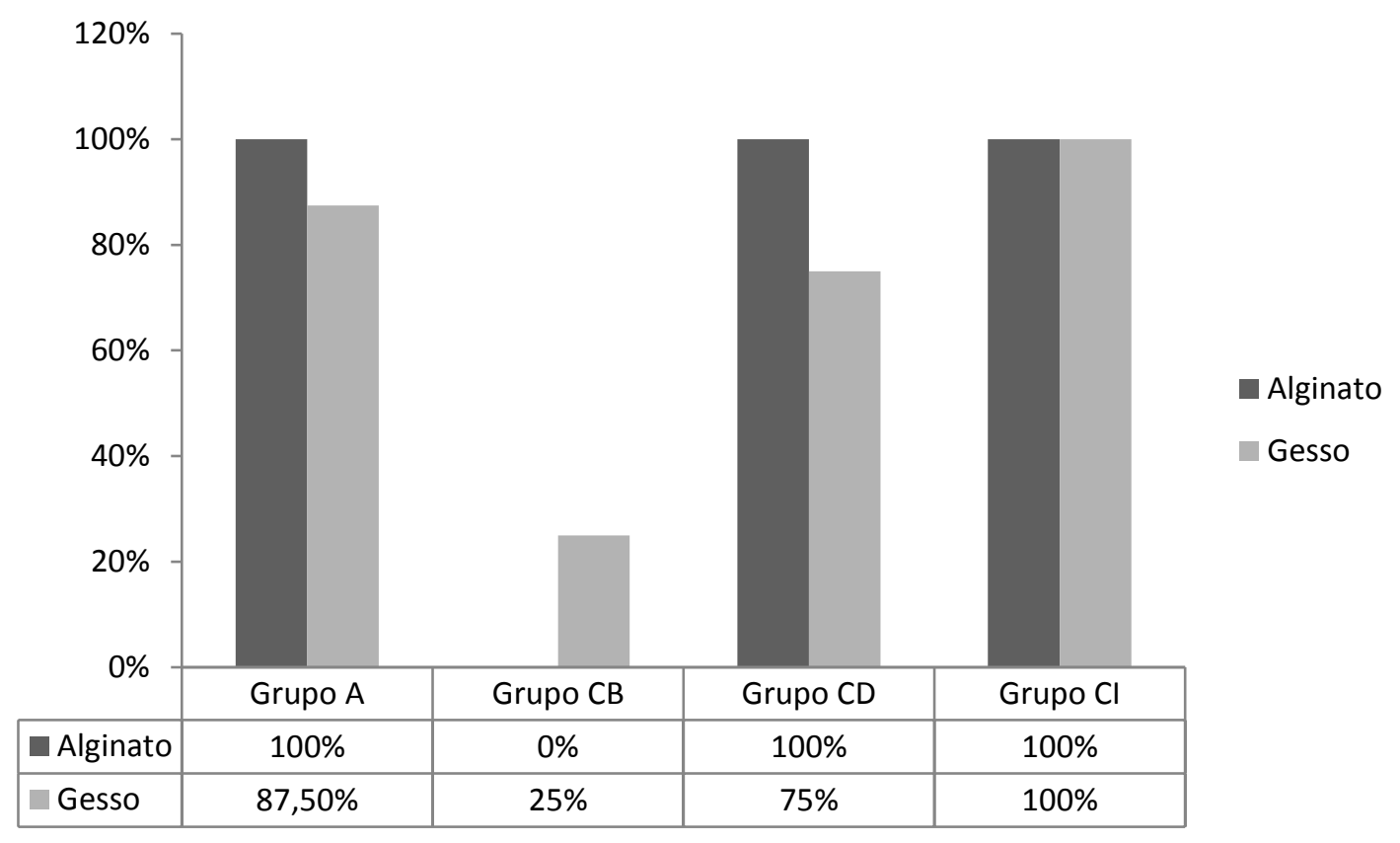

Gráfico 1: resultados do teste in vivo. 


\section{DISCUSSÃO}

A cavidade oral é um ambiente propício à colonização e transmissão de vários microrganismos presentes nos fluidos orais, sendo o sangue e a saliva meios ideais para que ocorra possível contaminação cruzada (THOMAZINI E.M., 2005). Assim, o alginato, em contato com o meio bucal do paciente no momento da moldagem, pode ser contaminado. Não havendo desinfecção do molde, posteriormente pode ocorrer também a contaminação do modelo de gesso (POWELL G.L. et al, 1990; OSÓRIO A.F. et al, 1998), com potencial risco de infecção cruzada no laboratório de prótese. A clorexidina conhecidamente apresenta amplo espectro de atividade antibacteriana e é utilizada em diversas especialidades da Odontologia (LOPES H.P. \& SIQUEIRA JR J.F., 2015), sendo de fácil acesso para os cirurgiões-dentistas.

Nesse estudo foi avaliada a eficácia da clorexidina na inibição do Streptococcus mutans, bactéria Gram-positiva presente na cavidade oral que se adere à superfície dentária e está associada à placa dental e à cárie (LEVINSON W., 2016). Os resultados demonstram que a clorexidina possuiu eficácia na inibição do crescimento de $S$. mutans em todas as formas testadas, seja ela borrifada sobre o molde de alginato, diluída durante a manipulação do alginato ou incorporada no pó de alginato, já na sua fabricação (Algitec®). ESTEVES et al (2007) também observaram a eficácia da clorexidina já incorporada no pó de alginato, o que também corrobora com os achados de MOREIRA E WANDERLEY-CRUZ (2005). CASEMIRO et al (2007) observaram a eficácia da clorexidina usada para manipulação do alginato, na concentração $0,2 \%$, sendo testado com o alginato comum e também no alginato com clorexidina incorporada (Greengel $\left.{ }^{\circledR}\right)$. Neste mesmo estudo, o teste com a clorexidina incorporada ao pó também comprovou-se eficaz. 
MOREIRA E WANDERLEY-CRUZ (2005), ESTEVES et al (2007) e CASEMIRO et al (2007) utilizaram uma metodologia semelhante ao presente estudo, utilizando o caldo BHI para o cultivo bacteriano, sendo semeado depois em placa de ágar sangue para a observação dos resultados.

Nos estudos de ESTEVES et al (2007) e de MOREIRA E WANDERLEY-CRUZ (2005) foram feitas avaliações do crescimento bacteriano nos tubos com caldo BHI, porém, em nosso estudo, ao analisar o caldo após o tempo de incubação, pudemos observar que havia turvação em todos os tubos devido à solubilidade dos corpos de prova de alginato, inviabilizando a análise visual, o que não é destacado nos estudos dos outros autores. Outra semelhança com o nosso estudo foi que CASEMIRO et al (2007) constatou que foi possível observar uma ligeira inibição no desenvolvimento de alguns microrganismos no alginato comum sem correlação com clorexidina.

Uma observação importante feita por CASEMIRO et al (2007) foi a constatação de que o método de preparação de hidrocolóides irreversíveis com uma solução de clorexidina a $0,2 \%$ na fórmula era mais eficaz do que a incorporação de um agente antimicrobiano durante a manipulação para reduzir a contaminação. Já HORTENSE et al (2010) afirma que a clorexidina incorporada aos hidrocolóides irreversíveis tem efeito antibacteriano, havendo uma inibição do crescimento de bactérias presentes na saliva. Entretanto, no teste in vivo, realizado com a população bacteriana normal da cavidade oral, constatou-se que o alginato com a clorexidina incorporada na fórmula e na manipulação não inibiu o crescimento bacteriano, portanto, não foram eficazes como agentes antibacterianos. Assim, a clorexidina borrifada no alginato mostrou-se ser a única eficaz na inibição do 
crescimento da população bacteriana da saliva, representando uma excelente opção para a prevenção de contaminações no molde e modelo da arcada dentária.

\section{CONCLUSÃO}

- No teste in vitro, a clorexidina se mostrou eficaz na inibição do Streptococcus mutans nos moldes de alginato em todas as formas testadas.

- O alginato comum (sem associação com a clorexidina) também exerce uma leve inibição no crescimento bacteriano. Entretanto, quando avaliando a situação do dia-adia, com a microbiota da cavidade oral dos voluntários, in vivo, pudemos verificar que a clorexidina borrifada após a geleificação foi o único método que provou ser eficaz na inibição do crescimento bacteriano em moldes de alginato e modelos de gesso.

- A clorexidina borrifada pode representar um importante método para prevenir a contaminação e potencial infecção cruzada.

\section{REFERÊNCIAS}

1. Anusavice K.J., Shen C., Rawls H.R. Phillips materiais dentários. $12^{\mathrm{a}}$ ed. Rio de Janeiro: Elsevier Editora Ltda; 2013. 595 p.

2. Maia S.C.M. Avaliação da estabilidade dimensional e reprodutibilidade dos materiais hidrocolóides irreversíveis submetidos à desinfecção química: uma revisão de literatura. 
Rio Grande do Sul: Universidade Federal do Rio Grande do Sul, Faculdade de Odontologia, 2016.

3. Powell G.L., Runnells R.D., Saxon B.A., Whisenant B.K. The presence and identification of organisms transmitted to dental laboratories. The Journal of Prosthetic Dentistry. 1990 Ago; 64 (2): 235-7.

4. Osório A.F., Fatturi C.C., Poisl M.I.P., Samuel S.M.W. Avaliação da eficácia de agentes químicos na desinfecção de moldes de alginato. Rev Fac Odontol Porto Alegre. 1998 Jul; 39 (1): 17-9.

5. Egusa H., Watamoto T., Matsumoto T., Abe K., Kobayashi M., Akashi Y., Yatani H. Clinical evaluation of the efficacy of removing microorganisms to disinfect patientderived dental impressions. Int J Prosthodont. 2008 Nov-Dez; 21(6): 531-8.

6. Borgo L.F., Bozzetti F.A., Flor J.F., Mello P.S., Kaiser T.D.L. Evaluation of bacterial contamination on irreversible hydrocolloid impressions before and after disinfection. Rev Bras Odontol. 2018; 75: 1-5. Avaliable from: URL: http://dx.doi.org/10.18363/rbo.v75.2018.e1091

7. Pakdin M., Soufiabadi S., Shahrakipour M. Evaluation of contamination reduction on gypsum casts from alginate impressions disinfected with four different materials. Global Journal of Health Science. 2016; 8 (12): 127- 132.

8. Hortense S.R., Carvalho E.S., Carvalho F.S., Silva R.P.R., Bastos J.R.M., Bastos R.S. Uso da clorexidina como agente preventivo e terapêutico na Odontologia. Rev Odontol Univ Cid São Paulo. 2010 Mai-Ago; 22 (2): 178-184. 
9. Russel A.D. Chlorhexidine: antibacterial action and bacterial resistance. Infection. 1986 Set-Out; 14 (5): 212-5.

10. Marion J., Pavan K., Arruda M.E.B.F., Nakashima L., Morais C.A.H. Chlorhexidine and its applications in Endodontics: A literature review. Dental Press Endod. 2013 SetDez; 3 (3): 36-54.

11. Lopes H.P., Siqueira Jr J.F. Endodontia:biologia e técnica. $4^{\mathrm{a}}$ ed. Rio de Janeiro: Elsevier Editora Ltda; 2015.848 p.

12. Moreira A.C.A., Wanderley-Cruz J.F. Efetividade da clorexidina incorporada a hidrocolóide irreversível. Rev Ciênc Méd Biol. 2005 Mai-Ago; 4 (2): 113-7.

13. Esteves R.A., Sousa E.G., Celestino Júnior A.F., Maranhão K.M., Pedrosa S.S., Gauch L.M.R. Análise da eficácia antimicrobiana dos alginatos autodesinfetantes. Rev Gaúcha Odontol. 2007 Jan-Mar; 55 (1); 23-8.

14. Oshiro Filho N.T., Coelho T.M.K., Schussler J.P., Insaurralde E., Leme M.P.L. Precisão dimensional de modelos obtidos de moldes de alginato: técnica da união de análogos. Arch Health Invest. 2018 Mai; 7 (5): 182-6.

15. Thomazini E.M. Biossegurança- controle de infecção cruzada na prática odontológica: manual de condutas. Faculdade de Odontologia de Piracicaba/UNICAMP; 2005. 63 p.

16. Levinson W. Microbiologia médica e imunologia.13th ed: Mc Graw Hill Brasil, 2016. 800 p.

17. Casemiro L.A., Pires-de-Souza F.C.P., Panzeri H., Martins C.H.G., Ito I.Y. In vitro antimicrobial activity of irreversible hydrocolloid impressions against 12 oral microorganisms. Braz Oral Res. 2007 Out-Dez; 21 (4): 323- 